\title{
Simple vaginal trachelectomy for early stage cervical cancer: A tertiary cancer center experience
}

\author{
Fuat Demirkiran ${ }^{1}$, Ilker Kahramanoglu ${ }^{1}$, Tugan Bese ${ }^{1}$, Hasan Turan ${ }^{1}$, Elif Meseci ${ }^{2}$, Macit Arvas ${ }^{1}$ \\ ${ }^{1}$ Division of Gynecologic Oncology, Department of Obstetrics and Gynecology, Cerrahpasa Faculty of Medicine, Istanbul Univer- \\ sity, Istanbul, Turkey \\ ${ }^{2}$ Department of Obstetrics and Gynecology, Acibadem Hospital, Istanbul, Turkey
}

\begin{abstract}
Objectives: Less radical fertility sparing procedures have been introduced to reduce morbidity and adverse obstetric outcome in cervical cancer. Our objective was to describe oncological and obstetric outcomes of women with early-stage cervical cancer who underwent a simple vaginal trachelectomy (SVT).

Material and methods: From 01/2013 to 05/2017, 14 women underwent SVT preceded by laparoscopic pelvic lymph node dissection.

Results: Patients' median age was 32 years and all of them were nulliparous. Histology included squamous cell carcinoma and adenocarcinoma in $12(85.7 \%)$ and $2(14.3 \%)$ patients, respectively. Three patients had stage $1 \mathrm{~A} 1$ with lymphovascular space invasion, $41 \mathrm{~A} 2$ and 7 1B1. After obtaining final histopathology, one patient underwent radical hysterectomy due to positive surgical margin and excluded from analysis. None of the patients had lymph node metastasis. None of the $13 \mathrm{pa}-$ tients developed a recurrence within a median follow-up of 27 (6-56) months. Seven patients have conceived: 4 were term deliveries, 2 were late preterm deliveries and 1 was spontaneous abortion.

Conclusions: SVT in well selected early-stage cervical cancer patients seems to be a safe treatment option with excellent oncologic outcome, preserving reproductive function. Literature data will need to be confirmed in large prospective series. Key words: cervical cancer, fertility-sparing, trachelectomy, lymphadenectomy
\end{abstract}

Ginekologia Polska 2018; 89, 9: 475-480

\section{INTRODUCTION}

Cervical cancer represents the second common malignancy in women worldwide, with an estimated 500,000 new cases and 275,000 related deaths annually [1]. In developed countries women tend to delay birth of first child until the age at the female reproductive capacity has started to decrease. Therefore, the number of patients with cervical cancer who desire fertility has been increased.

Radical hysterectomy with pelvic lymphadenectomy has been the standart treatment of stage $1 \mathrm{~A} 2$ and $1 \mathrm{~B} 1$ cervical cancer. However, radical trachelectomy, performed either by vaginal and abdominal route, represents as an effective treatment option with a survival rate of $95-98 \%$ in patients who desire fertility [2, 3]. Many guidelines propose radical trachelectomy with lymphadenectomy for early cervical cancer patients who wish to preserve fertility [4-6]. However, radical trachelectomy has some morbidities. Removal of unnecessary endocervical canal may lead to cervical stenosis in those patients [7]. Abortion and second trimester miscarriages are more than $70 \%$ in patients underwent abdominal radical trachelectomy. In addition, parametrectomy is responsible for the majority of surgical complications such as intraoperative significant blood loss, bladder and bowel dysfunction, fistula formation, and sexual dysfunction $[7,8]$. On the other hand, very low rate of parametrial involvement and recurrence in patients with cervical tumor $\leq 2 \mathrm{~cm}$ has been reported in many studies [9-11]. Analysis of more than 1000 cervical cancer cases with lesions measuring 
less than $2 \mathrm{~cm}$ found that the risk of parametrial infiltration is $<1 \%$ in this group of patients [10]. Retrospective data of 507 patients with stage $1 \mathrm{~B}$ or $2 \mathrm{~A}$ disease who underwent radical hysterectomy and pelvic lymphadenectomy revealed that patients having all of the following three pathological factors, inner $1 / 3$ stromal invasion and no lymphovascular space invasion (LVSI) and squamous histology, had 1.1\% risk of parametrial involvement [11]. A very recent series of 345 patients showed that none of the patients with tumor size less than $2 \mathrm{~cm}$ and no LVSI had parametrial involvement [12]. A retrospective review of 260 patients with early-stage cervical cancer managed with either simple hysterectomy or simple trachelectomy/conization and lymph node dissection demonstrated only 2 recurrences and 1 death in node-negative patients [13]. Standing these data, parametrectomy is highly questionable for many patients having cervical cancer $\leq 2 \mathrm{~cm}$. Thus, radicality of trachelectomy may be considered as unnecessary for this group of patients. While the parametrium and vaginal cuff along with cervix are removed during radical trachelectomy, simple vaginal trachelectomy (SVT) involves a supravaginal amputation of the cervix.

In this study, we describe our experiences with SVT in carefully selected cervical cancer patients with its oncological and obstetrical outcomes.

\section{MATERIAL AND METHODS}

Women who underwent less radical fertility sparing surgery for cervical cancer between 01/2013 and 05/2017 were retrospectively reviewed. The data, including age, parity, tumor size, histology and grade of the tumor, stage of the disease, presence of LVSI, pathological margins on diagnostic procedure and SVT follow-up evaluations were obtained from manuel reviews of patients' medical charts. Histologic type, grade and LVSI were determined by biopsy or LEEP. Tumor size was calculated using the findings from gynecological examination, transvaginal ultrasound and pelvic magnetic resonance imaging (MRI). Nodal status was assessed by Positron Emission Tomography (PET) scan.

Indications for different fertility sparing surgery procedures were discussed with patients from generally accepted to experimental. All patients were informed that the simple trachelectomy may be abandoned if any metastatic node was identified during laparoscopy.

All surgeries started with laparoscopic pelvic sentinel lymph node (SLN) mapping using methylene blue dye. SLNs were sent to frozen section evaluation. In the first 8 patients, complete bilateral pelvic lymphadenectomy was performed subsequently. The rest of the patients underwent only SLN mapping. If any sentinel lymph node was positive, SVT would be cancelled and laparoscopic paraaortic lymphad- enectomy would be planned. After negative frozen section result, SVT was performed in accordance with simple vaginal hysterectomy principle. SVT involved the amputation of the cervix and ligation of bilateral cervical branches of uterine arteries. The specimen was sent to frozen section for evaluation of the surgical margins. Then, isthmic edges were sutured to the vaginal edges. No cerclage was placed at the end of the procedure. Radical hysterectomy was planned in the presence of positive surgical margin. Ultrastaging study was performed for the SLNs.

All biopsy, LEEP and trachelectomy specimens were reviewed by same gynecopathologist. Patients were followed up at 4-months intervals for the first 2 years, then semiannually. Each visit included physical and gynecological examinations along with transvaginal ultrasonography, colposcopy and a vaginal cytology.

A detailed written informed consent was obtained from patients who opted for an experimental, less radical approach. The study was approved by the Ethics Committee of Istanbul University Cerrahpasa Faculty of Medicine.

Standart descriptive statistics were applied in the analysis. Statistical Package for the Social Sciences (SPSS) version 16.0 (SPSS Inc., Chicago, IL, USA) was used.

\section{RESULTS}

Fourteen women selected as candidates for SVT. None of them had a tumor larger than $20 \mathrm{~mm}$ on MRI or pelvic examination. None of them had a suspicious lymph node on PET scan. Of these, 13 women successfully completed fertility sparing surgery. One patient had positive surgical margin on final pathology and underwent laparoscopic radical hysterectomy and ovarian transposition. Clinicopathological characteristics of the study cohort are presented in Table 1. The median age of the patients was 32 (27-36); all of them were nulliparous. Most of the patients had squamous cell carcinoma. Cervical cancer was diagnosed from LEEP and punch biopsy in 10 and 3 patients, respectively. In one patient, cervical adenocarcinoma was diagnosed from cervical polypectomy.

The median operative time was 140 minutes (110200 minutes). No significant blood loss occured. There were no intraoperative or postoperative complications.

No recurrences occured within the median duration follow-up of 27 months (6-56 months). All follow-up cytology tests turned negative.

Among 11 women attempted to conceive, 7 patients have become pregnant spontaneously so far (63.6\%) (Tab. 2). From them, 1 had a spontaneous abortion in first trimester. 4 women successfully delivered at term. Two patients delivered in the 35th and 34th week of their pregnancies. All of the deliveries were cesarean sections. 
Table 1. Clinicopathological characteristics of the patients

\begin{tabular}{|c|c|}
\hline & Median (range) \\
\hline \multirow[t]{2}{*}{ Age [year] } & $32(27-37)$ \\
\hline & n (\%) \\
\hline $\begin{array}{l}\text { Parity } \\
0 \\
1\end{array}$ & $\begin{array}{l}14(100) \\
0\end{array}$ \\
\hline $\begin{array}{l}\text { Histology } \\
\text { Squamous } \\
\text { Adenocarcinoma }\end{array}$ & $\begin{array}{l}12(85.7) \\
2(14.3)\end{array}$ \\
\hline $\begin{array}{l}\text { Grade } \\
1 \\
2 \\
3\end{array}$ & $\begin{array}{l}6(42.8) \\
7(50) \\
1(7.1)\end{array}$ \\
\hline $\begin{array}{l}\text { Stage } \\
1 \mathrm{~A} 1 \text { with LVSI } \\
1 \mathrm{~A} 2 \\
1 \mathrm{~B} 1\end{array}$ & $\begin{array}{l}3(21.4) \\
4(28.5) \\
7(50)\end{array}$ \\
\hline $\begin{array}{l}\text { LVSI } \\
\text { No } \\
\text { Yes }\end{array}$ & $\begin{array}{l}7(50) \\
7(50)\end{array}$ \\
\hline $\begin{array}{l}\text { Diagnostic procedure } \\
\text { Punch bx } \\
\text { LEEP } \\
\text { Polyp excision }\end{array}$ & $\begin{array}{l}3(21.4) \\
10(71.4) \\
1(7.1)\end{array}$ \\
\hline $\begin{array}{l}\text { Pathological margins on diagnostic procedure } \\
\text { Negative } \\
\text { Positive }\end{array}$ & $\begin{array}{l}1(7.1) \\
13(92.9)\end{array}$ \\
\hline $\begin{array}{l}\text { Pathological margins on SVT specimen } \\
\text { Negative } \\
\text { Positive }\end{array}$ & $\begin{array}{c}13(92.9) \\
1(7.1)\end{array}$ \\
\hline
\end{tabular}

LVSI - lymphovascular space invasion; Bx — biopsy; LEEP — loop electrosurgical excision procedure; SVT — simple vaginal trachelectomy

Table 2. Obstetric outcomes of the 13 patients

\begin{tabular}{|l|l|}
\hline & $\mathbf{n}(\%)$ \\
\hline Attempted to conceive & $11(84.6)$ \\
\hline Patients achieved pregnancy & $7(63.6)$ \\
\hline Pregnancy results & $\mathbf{n}$ \\
Term birth ( $\geq 37$ weeks) & 4 \\
Preterm birth & 2 \\
Second trimester miscarriage & 0 \\
First trimester loss & 1 \\
\hline
\end{tabular}

\section{DISCUSSION}

Our study presents a cohort of patients with stage 1A2-1B1 cervical cancer who underwent SVT and laparoscopic pelvic lymphadenectomy. Median age of the 14 patients was 32 and all of them were nulliparous. The majority had stage 1B1 disease (50\%), squamous histology (85\%) and grade 1 or 2 lesions (93\%). Eight patients underwent laparoscopic SLN mapping followed by complete lymphadenectomy on both pelvic sides irrespective of whether the
SLN was found. SLNs were found unilaterally in 3 patients and bilaterally in 5 patients. In our clinic, completion pelvic lymphadenecomy has not been performed since August 2015 if SLNs was detected on both pelvic sides. The remaining 6 patients underwent only laparoscopic SLN mapping. Complete pelvic lymphadenectomy was not performed as at least one SLN was found per hemi-pelvises in these patients. In their study involving cervical cancer patients, Cibula et al. [14] performed ultrastaging to both sentinel and non-sentinel lymph nodes and found that there is no risk of occult metastasis on non-SLNs when SLNs are negative. In the present study, ultrastaging of SLNs resulted negative in every patients and pathologic evaluation of non-SLNs showed no metastasis in the first 8 patients.

The oncological outcomes of radical trachelectomy was shown to be comparable with radical hysterectomy [2]. However, oncologic safety of simple trachelectomy still remains debatable. In our series, with a median follow-up time of 27 months, there has been no recurrence so far. Oncologic outcome of our patients is similar to the literature. A previous study reported only 1 central invasive recurrence (3.2\%) out of 31 patients treated with SVT [15]. Another series showed 2 invasive recurrences in 38 patients who underwent large loop conization and pelvic lymphadecentomy [16]. Both studies included cervical cancer patients with tumors smaller than $2 \mathrm{~cm}$. A recent case series of 32 patients with stage 1A2-1B2 disease who underwent conization or simple trachelectomy reported an invasive recurrence rate of $12.5 \%$ (four of 32 patients). However, 10 patients received neoadjuvant chemotherapy and 3 out of 4 invasive recurrences were within the neoadjuvant chemotherapy group [17]. A multicenter study from Italy included 36 stage 1B1 cervical cancer cases treated with conization and lymphadenectomy [18]. Fourteen percent of the patients had grade 3 disease and $14 \%$ had LVSI. One pelvic lymph node recurrence occured within 66 months follow-up time. In their first report, Plante et al. [19] reported no recurrence in 16 patients with low risk, early-stage cervical cancer $(<2 \mathrm{~cm})$ who underwent SVT with SLN mapping and/or pelvic lymph node dissection within 27 months follow-up time. Four years later, they presented a larger series of SVT including a total of 35 patients $(n=8$ : stage $1 \mathrm{~A} 1$ with LVSI; $n=9$ : stage $1 A 2 ; n=18$ : stage $1 B 1$ ). They reported only one local recurrence [19].

Among our patients, 7 women have become pregnant. First trimester loss occured in one patient, 2 delivered at 34 and 35 weeks, and 4 delivered at term ( $>37$ weeks). Our obstetric outcome is in keeping with the literature. Plante et al. [20] reported 18 term and 2 preterm births in 35 patients who underwent SVT with a median follow-up time of 42 months. A large, systematic review comparing obstetric outcomes of radical and simple trachelectomy found that, 


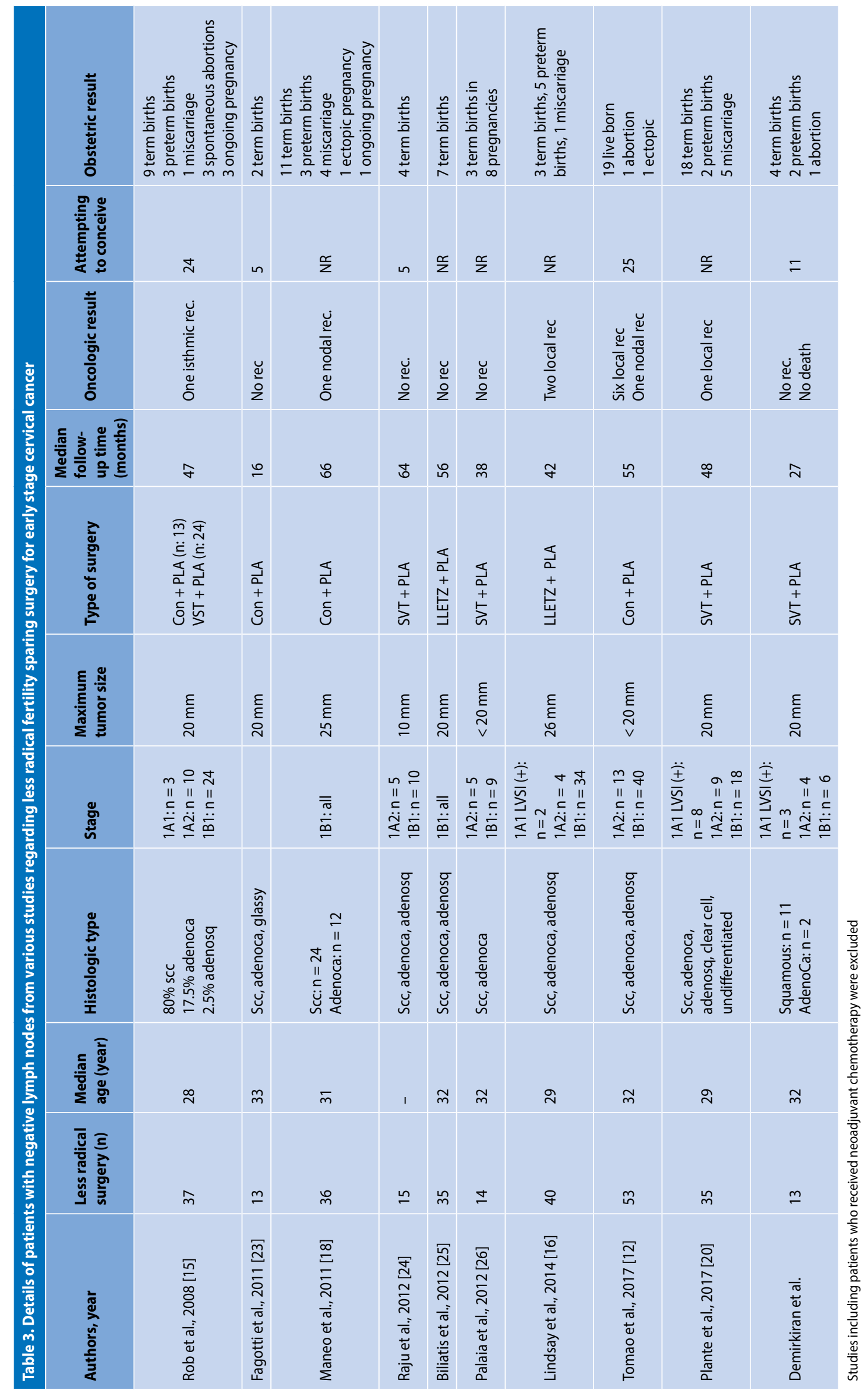


the prematurity rate is significantly lower in patients who underwent SVT or conization compared to vaginal or abdominal radical trachelectomy [21].

Slama et al. [17] pointed out the importance of selection of the patients with an active attitude to their reproductive plans, in order to avoid risk of recurrences and death in a group of patients with excellent outcome after standart procedure. In their study, half of the patients did not consider pregnancy for a reason after conization or simple trachelectomy for cervical cancer. Clearly, careful patient selection is of paramount importance. We agree with Plante [22] that these cases should be evaluated and managed by gynecologic oncologists.

To date, less than 400 women with early-stage cervical cancer managed with conservative fertility sparing surgery (conization or simple trachelectomy with pelvic lymphadenectomy) have been described in the literature. Table 3 summarizes the detailed data of these series. Among them, there were 3 patients with a histologic type other than squmous, adeno- or adenosquamous carcinoma (clear cell, glassy and undifferantiated types). Most women had stage 1B1 disease. Only one patient had a tumor larger than $2 \mathrm{~cm}$. Median follow up time ranged from 16 to 66 months. Recurrence rate among shown studies was about $4 \%$. Ninety-eight live births with $>70 \%$ being term,among 245 women attempted to concieve have been reported.

Currently, there are ongoing one randomised clinical trial (the SHAPE trial) and two prospective cohort studies (ConCerv and GOG-278) evaluating the safety of less radical surgery in patients with low-risk early-stage cervical cancer [27-29]. These trials will provide more concrete evidence on this issue.

\section{CONCLUSIONS}

In conclusion, SVT can be an effective treatment option in selected group of cervical cancer patients who strongly desire fertility preservation. Based on existing literature and our data, we suggest performing SVT to patients with cervical tumors $2 \mathrm{~cm}$ or less in diameter. Results of three ongoing prospective studies should be waited to reach more reliable conclusion.

\section{Conflict of interest}

The authors declare that there is no conflict of interest.

\section{Acknowledgments}

None.

\section{REFERENCES}

1. Jemal A, Bray F, Center MM, et al. Global cancer statistics. CA Cancer J Clin. 2011; 61(2): 69-90, doi: 10.3322/caac.20107, indexed in Pubmed: 21296855.
2. Rob L, Skapa P, Robova H. Fertility-sparing surgery in patients with cervical cancer. The Lancet Oncology. 2011; 12(2): 192-200, doi: 10.1016/s1470-2045(10)70084-x.

3. Gien LT, Covens A. Fertility-sparing options for early stage cervical cancer. Gynecol Oncol. 2010; 117(2): 350-357, doi: 10.1016/j.ygyno.2010.01.039, indexed in Pubmed: 20163850.

4. National Comprehensive Cancer Network. Cervical Cancer (Version 2.2015). http://www.nccn.org/professionals/physician_gls/pdf/cervical. pdf. (20.09.2017).

5. Lim MC, Lee M, Shim SH, et al. Practice guidelines for management of cervical cancer in Korea: a Korean Society of Gynecologic Oncology Consensus Statement. J Gynecol Oncol. 2017; 28(3): e22, doi: 10.3802/jgo.2017.28.e22, indexed in Pubmed: 28382794.

6. Marth C, Landoni F, Mahner S, et al. ESMO Guidelines Committee, ESMO Guidelines Committee. Cervical cancer: ESMO Clinical Practice Guidelines for diagnosis, treatment and follow-up. Ann Oncol. 2017 28(suppl_4): iv72-iv83, doi: 10.1093/annonc/mdx220, indexed in Pubmed: 28881916.

7. Speiser D, Malik S, Lanowska M, et al. Follow-up after radical vaginal trachelectomy (RVT): patients' problems and physicians' difficulties. Arch Gynecol Obstet. 2017; 296(3):559-564, doi: 10.1007/s00404-017-4463-0, indexed in Pubmed: 28717824.

8. Bouchard-Fortier G, Reade CJ, Covens A. Non-radical surgery for small early-stage cervical cancer. Is it time? Gynecol Oncol. 2014; 132(3):624627, doi: 10.1016/j.ygyno.2014.01.037, indexed in Pubmed: 24480237.

9. Frumovitz M, Sun CC, Schmeler KM et al. Parametrial involvement in radical hysterectomy specimens for women with early-stage cervical cancer. Obstet Gynecol. 2009; 114(1): 93-99, doi: 10.1097/AOG.0b013e3181ab474d, indexed in Pubmed: 19546764.

10. Schmeler KM, Frumovitz M, Ramirez PT. Conservative management of early stage cervical cancer: is there a role for less radical surgery? Gynecol Oncol. 2011; 120(3):321-325, doi: 10.1016/j.ygyno.2010.12.352, indexed in Pubmed: 21320670.

11. Xie X, Song K, Cui B, et al. Significance of the Factors Associated With Parametrial Involvement in Stage IB to IIA Cervical Cancer. Int J Gynecol Cancer. 2016; 26(5): 939-943, doi: 10.1097/IGC.0000000000000688, indexed in Pubmed: 26905336.

12. Tomao F, Maruccio M, Preti EP, et al. Conization in Early Stage Cervical Cancer: Pattern of Recurrence in a 10-Year Single-Institution Experience. Int J Gynecol Cancer. 2017; 27(5): 1001-1008, doi: 10.1097/IGC.0000000000000991, indexed in Pubmed: 28486242.

13. Ramirez PT, Pareja R, Rendón GJ, et al. Management of low-risk early-stage cervical cancer: should conization, simple trachelectomy, or simple hysterectomy replace radical surgery as the new standard of care? Gynecol Oncol. 2014; 132(1): 254-259, doi: 10.1016/j.ygyno.2013.09.004, indexed in Pubmed: 24041877.

14. Cibula D, Zikan M, Slama J, et al. Risk of micrometastases in non-sentine pelvic lymph nodes in cervical cancer. Gynecol Oncol. 2016; 143(1): 83-86, doi: 10.1016/j.ygyno.2016.07.101, indexed in Pubmed: 27421753.

15. Rob $L$, Pluta $M$, Strnad $P$, et al. A less radical treatment option to the fertility-sparing radical trachelectomy in patients with stage I cervical cancer. Gynecol Oncol. 2008; 111(2 Suppl): S116-S120, doi: 10.1016/j. ygyno.2008.07.021, indexed in Pubmed: 18725167.

16. Lindsay $R$, Burton $K$, Shanbhag $S$, et al. Fertility conserving management of early cervical cancer: our experience of LLETZ and pelvic lymph node dissection. Int J Gynecol Cancer. 2014; 24(1): 118-123, doi: 10.1097/IGC.0000000000000023, indexed in Pubmed: 24300465.

17. Slama J, Cerny A, Dusek L, et al. Results of less radical fertility-sparing procedures with omitted parametrectomy for cervical cancer: 5 years of experience. Gynecol Oncol. 2016; 142(3): 401-404, doi: 10.1016/j. ygyno.2016.07.008, indexed in Pubmed: 27396943.

18. Maneo A, Sideri M, Scambia G, et al. Simple conization and lymphadenectomy for the conservative treatment of stage IB1 cervical cancer. An Italian experience. Gynecol Oncol. 2011; 123(3): 557-560, doi: 10.1016/j. ygyno.2011.08.009, indexed in Pubmed: 21907396.

19. Plante $M$, Gregoire J, Renaud $M C$, et al. Simple vaginal trachelectomy in early-stage low-risk cervical cancer: a pilot study of 16 cases and review of the literature. Int J Gynecol Cancer. 2013; 23(5): 916-922, doi: 10.1097/IGC.0b013e3182954ddf, indexed in Pubmed: 23669441.

20. Plante M, Renaud MC, Sebastianelli A, et al. Simple Vaginal Trachelectomy: A Valuable Fertility-Preserving Option in Early-Stage Cervical Cancer. Int J Gynecol Cancer. 2017; 27(5): 1021-1027, doi: 10.1097/IGC.0000000000000989, indexed in Pubmed: 28498240. 
21. Bentivegna $\mathrm{E}$, Maulard $\mathrm{A}$, Pautier $\mathrm{P}$, et al. Fertility results and pregnancy outcomes after conservative treatment of cervical cancer: a systematic review of the literature. Fertil Steril. 2016; 106(5): 1195-1211.e5, doi: 10.1016/j.fertnstert.2016.06.032, indexed in Pubmed: 27430207.

22. Plante M. Evolution in fertility-preserving options for early-stage cervical cancer: radical trachelectomy, simple trachelectomy, neoadjuvant chemotherapy. Int J Gynecol Cancer. 2013; 23(6): 982-989, doi: 10.1097/IGC.0b013e318295906b, indexed in Pubmed: 23792600.

23. Fanfani F, Landoni F, Gagliardi ML, et al. Excisional cone as fertility-sparing treatment in early-stage cervical cancer. Fertil Steril. 2011; 95(3): 1109-1112, doi: 10.1016/j.fertnstert.2010.11.010, indexed in Pubmed: 21122837.

24. Raju SK, Papadopoulos AJ, Montalto SA, et al. Fertility-sparing surgery for early cervical cancer-approach to less radical surgery. Int J Gynecol Cancer. 2012; 22(2): 311-317, doi: 10.1097/IGC.0b013e3182370f51, indexed in Pubmed: 22237381.
25. Biliatis I, Kucukmetin A, Patel A, et al. Small volume stage 1B1 cervical cancer: Is radical surgery still necessary? Gynecol Oncol. 2012; 126(1): 73-77, doi: 10.1016/j.ygyno.2012.03.041, indexed in Pubmed: 22465521.

26. Palaia I, Musella A, Bellati F, et al. Simple extrafascial trachelectomy and pelvic bilateral lymphadenectomy in early stage cervical cancer. Gynecol Oncol. 2012; 126(1): 78-81, doi: 10.1016/j.ygyno.2012.04.004, indexed in Pubmed: 22487540.

27. Plante M. The SHAPE trial. http://www.gcig.igcs.org/Spring2012/2012 june_shape_trial.pdf..

28. M.D. Anderson Cancer Center. Conservative surgery for women with cervical cancer. http://clinicaltrials.gov/show/NCT01048853 NLM Identifier: NCT 01048853.

29. Covens A. GOG Protocol 278. http://www.gcig.igcs.org/Spring2012/2012 june_cervix_cancer_committee.pdf. 